\title{
The value and awareness of a community kitchen resource in Huntly, Aberdeenshire, a semi rural town: a qualitative analysis
}

\author{
W. L. Wrieden and K. Reid \\ Robert Gordon University, Aberdeen, AB25 IHG
}

It has been reported that local food projects enable communities to integrate, share information and skills, and work best when more than food is the focus ${ }^{(1)}$. Huntly, Aberdeenshire (AB54) is a semi-rural town, population 4461 , identified as an area of deprivation, most especially in education, skills and training ${ }^{(2)}$. A community kitchen has been in existence for 18 months. The broad aim of this facility is to use food, nutrition and cooking to promote physical and mental wellbeing and social inclusion.

This research sought to assess awareness of the community kitchen in the general population of Huntly and whether the use of the community kitchen improves knowledge and therefore consumption of a healthier diet? It was to be used as a barometer of opinion to determine the feasibility of establishing a similar facility in another area.

A questionnaire was developed and distributed to 1991 households in the AB54 area. Of the 384 people (19\% of households) who responded, over two-thirds were female, 190 people were aware of the facility and 25 of these had used it. Respondents were encouraged to write their own comments and these comments were thematically analysed by two researchers independently and a preliminary coding frame developed ${ }^{(3)}$. Six predominant themes were identified: perceived benefits; unclear/unknown purpose; time; confidence; role of education and schools; perceived personal and social disbenefits. Nearly half the respondents considered that the community kitchen was a good idea but a minority questioned the use of public funds for the project. Time was cited as a factor as why some did not use the facility or prepare meals from fresh food. Some expressed confidence in their own abilities but emphasised the need for increasing cooking confidence and skills in others, and for cooking skills to be taught in schools. A typical comment included several themes:

"I use a ready meals/ takeaways only when there is a lack of time to prepare a home cooked meal e.g. work or evening commitments. If the kitchen's purpose is to teach cooking skills to those who don't have them then yes. Too many children miss out on basic cooking skills in school nowadays in favour of other subjects." Respondent aged 46-55 years with income >£400 per week, commenting in reply to question "Is the community kitchen a good idea?"

Although the majority of respondents gave generally encouraging comments, the fact that only one fifth of households responded and one fifth of these were unaware or unsure of the purpose of the facility indicates that the feeling encapsulated in the following may be more widespread:

“Needs more publicity. Lived here all my life and never heard of it" Respondent aged >55 years with income $£ 151-200$ per week.

Community food projects should be seen in the wider context of enabling individuals to take some control of personal health and well being as well as improving life skills, building confidence and establishing social inclusion. They must also be sustainable and progressive; possessing ability to integrate into the community they serve. This research suggests that the Huntly community kitchen is regarded favourably by those who understand its purpose. However, the barriers perceived by the public should be continually addressed to encourage knowledge, awareness and, if appropriate, participation in the community kitchen by as many of the population as possible.

With thanks to the Huntly Food and Health Group, the Huntly community for their participation and to Dr Flora Douglas for advice

1. McGlone P, Dobson B, Dowler E et al. (1999) Food projects and how they work. York: Joseph Rowntree Foundation.

2. Aberdeenshire Council (2009) Deprivation analysis. Scottish index of multiple deprivation 2009: Aberdeenshire. http://www.aberdeenshire.gov.uk/ statistics/economic/deprivation.asp (accessed January 2012).

3. Draper AK (2004) Proc Nutr Soc 63, 641-646. 